\title{
Experimental and Numerical Investigation of Thickness Distribution in Forming of Superplastic Zn-22Al Alloy
}

\author{
${ }^{1 *}$ Mehmet Emin Çetin, ${ }^{2}$ Muhammet Demirtaş, ${ }^{3}$ Gençağa Pürçek, ${ }^{3}$ Ömer Necati Cora, ${ }^{3}$ Hasan Sofuoğlu \\ ${ }^{* 1}$ Necmettin Erbakan University, Department of Space and Satellite Engineering, Konya, Turkey \\ ${ }^{2}$ Bayburt University, Department of Mechanical Engineering, Bayburt, Turkey \\ ${ }^{3}$ Karadeniz Technical University, Department of Mechanical Engineering, Trabzon, Turkey
}

\begin{abstract}
:
In this study, formability of superplastic $\mathrm{Zn}-22 \mathrm{Al}$ alloy was investigated experimentally and numerically at room temperature (RT). To this goal, $\mathrm{Zn}-22 \mathrm{Al}$ alloy was wrought and grain size of the alloy was decreased to $200 \mathrm{~nm}$ by means of equal channel angular extrusion (ECAE), first. Then, Erichsen tests were conducted at $1 \times 10^{-1} \mathrm{~s}^{-1}, 1 \times 10^{-2} \mathrm{~s}^{-1}, 1 \times 10^{-3} \mathrm{~s}^{-1}$ strain rates. After experimental work, Ls-Dyna finite element software was used for numerical analysis of Erichsen test to compare the thickness distribution obtained both experimentallyand numerically . It was shown that $\mathrm{Zn}-22 \mathrm{Al}$ alloy had room temperature superplasticity and superplastic forming could be modeled accurately enough using FEA based on the good fit between numerical and experimental results.
\end{abstract}

Keywords: Superplasticty, Zn-22Al Alloy, Erichsen Test, Finite Element Method

\section{Özet:}

$\mathrm{Bu}$ çalışmada, süperplastik Zn-22Al alaşımının oda sıcaklığındaki şekillendirilebilirliği deneysel ve sayısal olarak incelenmiştir. İlk olarak, Zn-22Al alaşımı döküm yoluyla üretilmiş ve eş kanallı açısal ekstrüzyon (EKAE) yöntemi uygulanarak tane boyutu $200 \mathrm{~nm}$ düşürülmüştür. Erichsen testleri $1 \times 10^{-1}$, $1 \times 10^{-2}$ ve $1 \times 10^{-3} \mathrm{~s}^{-1}$ deformasyon hızlarında gerçekleştirilmiştir. Deneysel çalışma sonrası, Ls-Dyna sonlu elemanlar yazılımı kullanılarak Erichsen testinin sonlu elemanlar analizleri yapılmış, deneysel ve sayısal olarak elde edilen kalınlık değişimleri karşılaştırılmıştır. Zn-22Al alaşımının oda sıcaklığında süperplastik şekillendirilebildiği gösterilmiş, ve bu malzeme için elde edilen deneysel ve sayısal sonuçlar arasındaki uyum göz önüne alındığında süperplastik şekillendirmenin sonlu elemanlar yöntemi ile kabul edilebilir sınırlar içinde modellenebildiği gösterilmiştir.

Anahtar Kelimeler: Süperplastisite, Zn-22Al Alaşımı, Erichsen Testi, Sonlu Elemanlar Yöntemi

\section{Giriş}

Süperplastik malzemeler düşük deformasyon hızlarında ve yüksek sıcaklıklarda aşırı çekme uzaması gösterebilen ince tane yapısına sahip malzemelerdir [1]. Bu tür malzemelerin gösterdiği yüksek çekme uzaması süperplastik şekilllendirme teknolojisinin gelişmesine öncülük etmiştir. Süperplastik şekillendirme teknolojisi, havacılık, iletişim, mimarlık ve tıp alanlarında uygulama alanlarına sahip olmakla beraber bu yöntemle tek bir şekillendirme işlemiyle son boyutlara yakın

*Corresponding author: Address: Necmettin Erbakan University, Department of Space and Satellite Engineering, Konya, Turkey. E-mail address: mecetin@konya.edu.tr, Phone: +903323252024 
ölçülerde parçalar elde edilebilmektedir [2]. Malzemelerin süperplastik özellik gösteribilmesi için $10 \mu \mathrm{m}$ 'den küçük tane yapısına sahip olmaları, $10^{-4}-10^{-2} \mathrm{~s}^{-1}$ deformasyon hızlarında veergime noktası sıcaklıklarının yarısının üzerinde (Kelvin cinsinden) şekillendirilmeleri gereklidir [1,3]. Fakat, tane boyutunun küçültülmesi sayesinde süperplastik davranışın elde edildiği sıcaklığın düştüğü ve gerekli deformasyon hızının arttığı belirlenmiştir [3,4]. Malzemelerin tane boyutunu küçültmenin yollarından biri de eş kanallı açısal ekstrüzyon yöntemidir. $\mathrm{Bu}$ yöntem sayesinde $100 \mathrm{~nm}$ ortalama tane boyutuna sahip malzemeler üretilebilmektedir [5].

Literatürde süperplastik malzemelerden Zn-22Al alaşımının şekillendirilebilirliği tek eksenli çekme deneyi ile bir çok çalışmada incelenmiştir [1,3,6-10,11]. Süperplastik Zn-22Al alaşımında tane boyutunun tek eksenli ve iki eksenli şekillendirilebilirliğine etkisi araştırmacılar tarafindan daha önce incelenmiştir [12,13]. Bu çalışmada ise Zn-22Al alaşımının iki eksenli şekillendirilebilirliği kalınlık değişimi etkisi üzerinden deneysel ve sayısal olarak incelenmiştir.

\section{Deneysel Çalışmalar}

Zn-22Al alaşımı \% 99 saflıkta Zn ve \% 99 saflıkta Al alaşımlarından kokil kalıba döküm yöntemiyle üretilmiştir. Döküm sonrası ürün oda sıcaklığında soğutulmuştur. Daha sonra, $375{ }^{\circ} \mathrm{C}$ 'de 24 saat homojenizasyon tavlamasına tabi tutulmuştur. Bu işlemi takiben, EKAE için gerekli olan $13 \times 13 \times 120 \mathrm{~mm}^{3}$ boyutunda numuneler talaşlı imalat yöntemleri kullanılarak elde edilmiştir. EKAE öncesi numuneler $375{ }^{\circ} \mathrm{C}$ 'de 48 saat homojenizasyon tavlamasına tabi tutulmuştur ve su verme işlemi gerçekleştirilmiştir. EKAE işlemi $350{ }^{\circ} \mathrm{C}$ 'de rota $\mathrm{Bc}$ takip edilerek 4 paso ve oda sıcaklığında rota Bc takip edilerek 4 paso şeklinde gerçekleştirilmiştir. 0,7 mm kalınlığında Erichsen numuneleri ekstrüzyon yönüne dik doğrultuda tel erozyon yardımıyla kesilerek çıkarılmıştır (Şekil 1). Erichsen testleri $1 \times 10^{-1} \mathrm{~s}^{-1}, 1 \times 10^{-2} \mathrm{~s}^{-1}, 1 \times 10^{-3} \mathrm{~s}^{-1}$ deformasyon hızlarında Instron 3382 cihazı kullanılarak gerçekleştirilmiştir. Deneysel çalışmalar ile ilgili detaylı bilgiler literatürde mevcuttur. [11-13]. Deneyler sonrasında Erichsen numuneleri çatlak başlangıcının olduğu kısımlar göz önüne alınarak tel erozyon yardımıyla orta kısımlarından kesilmiştir. Kesilen numunelerin SEM resimleri çekilmiş ve Image J yazılımı kullanılarak numune kesidinde eğri boyunca kalınlık değişimi elde edilmiştir. 
EKAE numunesi

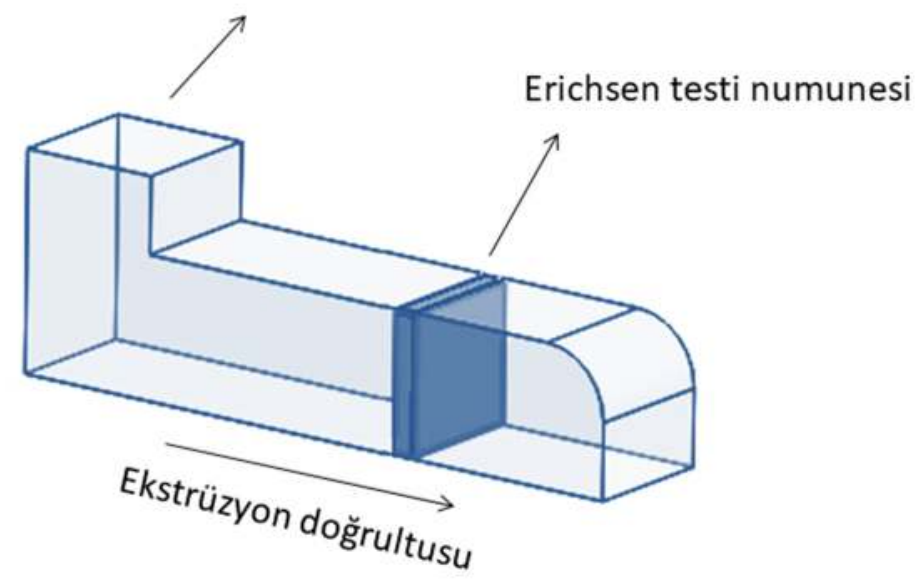

Şekil 1. EKAE işlemi uygulanmış numune içerisinde Erichsen numunesinin konumu

\section{Sayısal Analizler}

Erichsen testlerinin sonlu eleman analizi için Ls-Dyna yazılımı kullanılmışırı. Sac, zımba, tutucu ve kalıp bileşenleri .iges formatında Solidworks yazılımında yüzey olarak çizilmiştir. Hyperworks yazılımında ise sac, zımba, tutucu ve kalıp bileşenleri için sonlu elemanlar ağ örgüsü (meshing) oluşturulmuştur. A $\breve{g}$ örgüsünde kullanılan eleman sayıları Tablo 1'de gösterilmiştir. Erichsen testinin sonlu eleman modeli, Ls-Dyna yazılımında malzeme özelliklerinin girilmesi, sınır şartlarının oluşturulması aşamalarından sonra hazır hale gelmiştir. Erichsen testi için oluşturulan sonlu elemanlar modeli Şekil 2'de gösterilmiştir. Malzeme modeli olarak MAT 64 "Strain rate power law plasticity" modeli kullanılmıştır. Bu malzeme modeli için gerekli olan değerler, yazarların daha önce yaptıkları çalışmalardan elde edilmiştir [11] (Tablo 2). Sac-sac tutucu, sac-kalıp, sac-zımba temas bölgelerindeki sürtünme katsayısı 0,05, 0,05 ve 0,2 olarak uygulanmıştır. Bütün temas yüzeyleri için yüzeyden yüzeye şekillendirme (surface to surface) Ls-Dyna temas kartı tercih edilmiştir. Sonlu elemanlar analizleri sonrasında, $1 \times 10^{-1} \mathrm{~s}^{-1}, 1 \times 10^{-2} \mathrm{~s}^{-1}$, $1 \times 10^{-3} \mathrm{~s}^{-1}$ deformasyon hızları için parça merkezinden kenara doğru uzanan eğri boyunca kalınlık değişimi grafikleri oluşturulmuştur.

Tablo 1. Erichsen testinin sonlu elemanlar modelinde kullanılan eleman sayıları

\begin{tabular}{|c|c|c|c|c|}
\hline Parça Adı & Sac & Kalıp & Zımba & Baskı Plakası \\
\hline Eleman Sayısı & 3058 & 1250 & 1400 & 250 \\
\hline Eleman Tipi & $\begin{array}{c}\text { Kabuk } \\
\text { (Element Type 2) }\end{array}$ & $\begin{array}{c}\text { Kabuk } \\
\text { (Element Type 2) }\end{array}$ & $\begin{array}{c}\text { Kabuk } \\
\text { (Element Type 2) }\end{array}$ & $\begin{array}{c}\text { Kabuk } \\
\text { (Element Type 2) }\end{array}$ \\
\hline
\end{tabular}




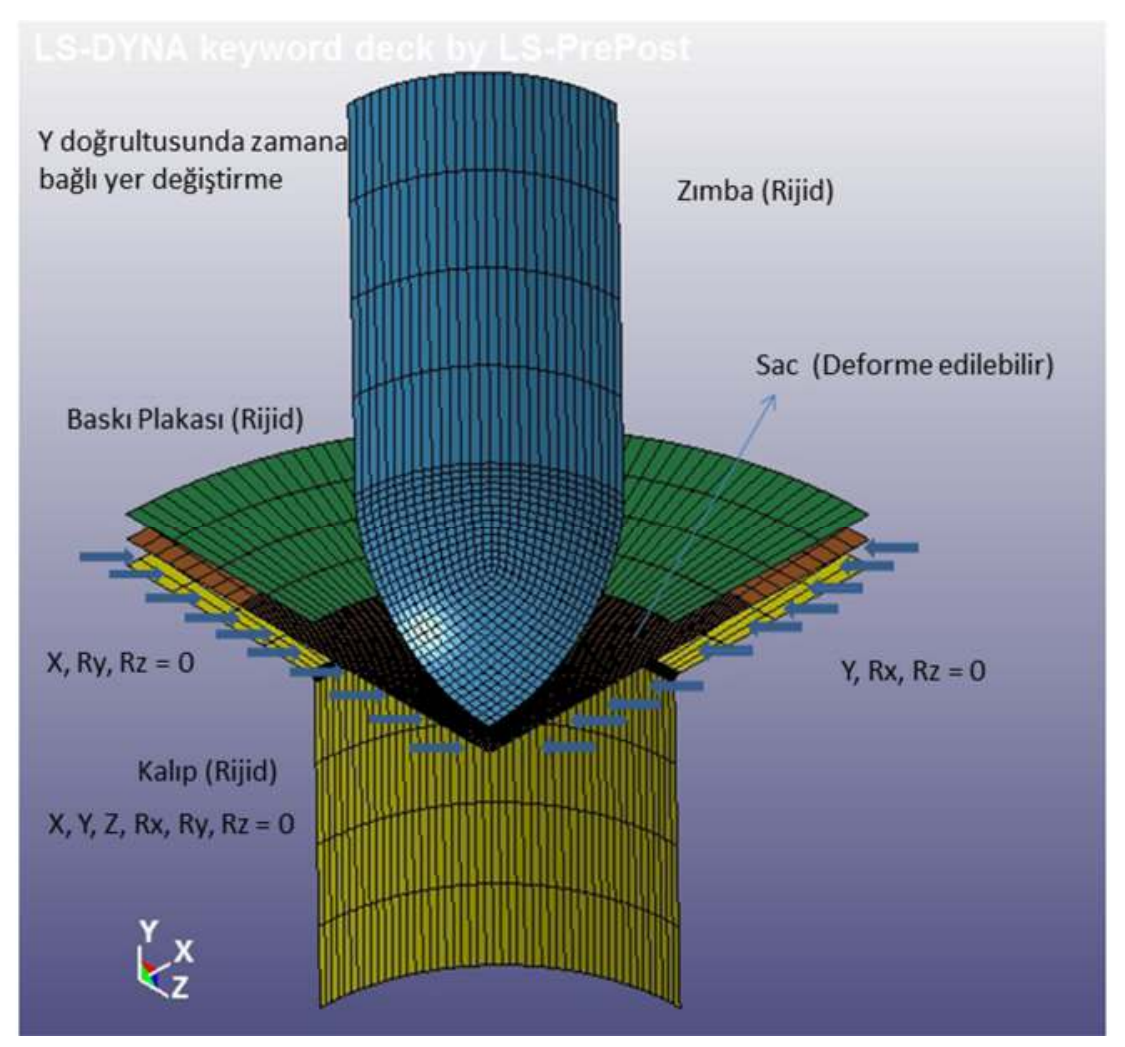

Şekil 2. Erichsen testinin sonlu elemanlar modeli ve sınır şartları

Tablo 2. Zn-22Al alaşımı Mat 64 malzeme parametreleri [11]

\begin{tabular}{|l|c|c|c|}
\hline Parametre & $\mathbf{1 x 1 0}^{-1} \mathbf{s}^{-\mathbf{1}}$ & $\mathbf{1 \times 1 0 ^ { - 2 }} \mathbf{s}^{-\mathbf{1}}$ & $\mathbf{1 \times 1 0}^{-\mathbf{3}} \mathbf{s}^{-\mathbf{1}}$ \\
\hline Yoğunluk (g/mm $\mathbf{3})$ & $5,2 \times 10^{-9}$ & $5,2 \times 10^{-9}$ & $5,2 \times 10^{-9}$ \\
\hline Poisson Oranı & 0,3 & 0,3 & 0,3 \\
\hline Elastisite Modülü (MPa) & 13436 & 13436 & 13436 \\
\hline Malzeme Sabiti (K) (MPa) & 260 & 186 & 110 \\
\hline Deformasyon Sertleșme Üssü & 0,07 & 0,08375 & 0,074 \\
\hline Deformasyon Hızı Duyarılılı İndisi & 0,3 & 0,16 & 0,16 \\
\hline
\end{tabular}

\section{Bulgular}

Süperplastik Zn-22Al alaşımının oda sıcaklığında şekillendirilebilirliğine tane boyutunun etkisi yazarların daha önceki çalışmalarında incelenmiştir [11]. Detaylı tartışma ve sonuçlara bu çalışmada yer verilmiştir. Bu çalışmada Erichsen testinde elde edilen kalınlık değişimleri ilgili testin sayısal analizinden elde edilen kalınlık değişimleri ile karşılaştırılmıştır. Zn-22Al alaşımına iki adımlı EKAE işlemi sonrasında $1 \times 10^{-1} \mathrm{~s}^{-1}, 1 \times 10^{-2} \mathrm{~s}^{-1}, 1 \times 10^{-3} \mathrm{~s}^{-1}$ deformasyon hızlarında 
uygulanan Erichsen testleri ve bu testlerin sayısal olarak modellenmesinden elde edilen kalınlık değişimlerinin karşılaştırılmasını içeren grafikler Şekil 3- Şekil 5'te gösterilmiştir. Bu grafikler incelendiğinde deneysel ve sayısal sonuçlar arasında yüksek oranda uyum gözlenmektedir. Numune üzerinde incelme sonucu kopmanın gerçekleşeceği bölgeler doğru olarak tahmin edilmiş; bunun yanısıra kalınlık artışı ve incelmenin olduğu bölgelerde sayısal analizler deneysel sonuçlarla benzer trendleri sergilemiştir. Şekil 5 'te sayısal ve deneysel olarak elde edilen kesit resimleri kalınlık değişimi açısından karşılaştırılmıştır.

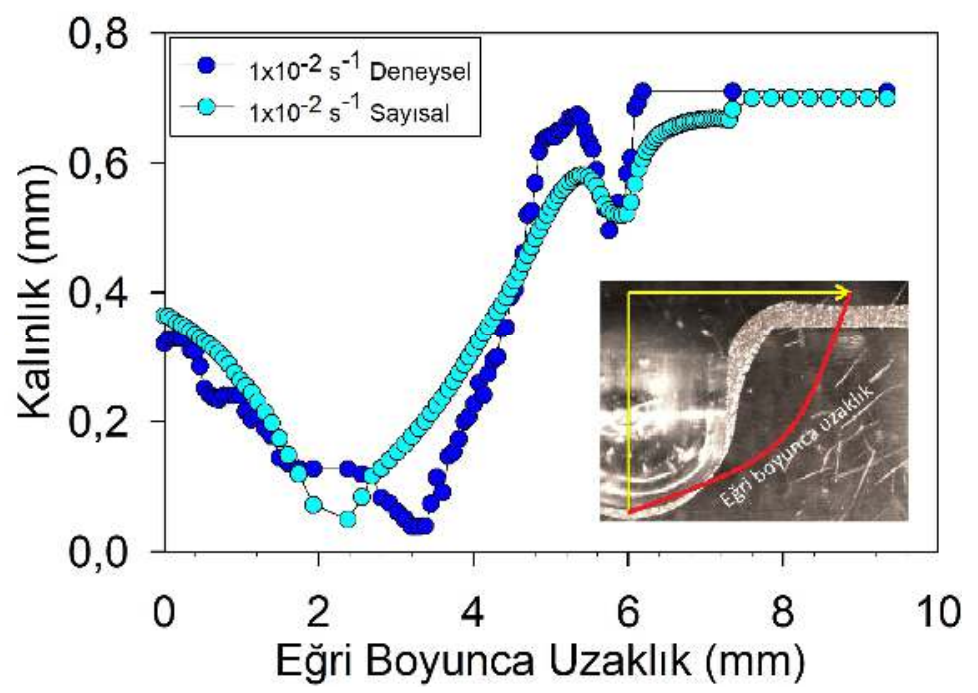

Şekil 3. Zn-22Al alaşımının $1 \times 10^{-1} \mathrm{~s}^{-1}$ deformasyon hızında yapılan Erichsen testinde elde edilen parça kalınlığı değişimi

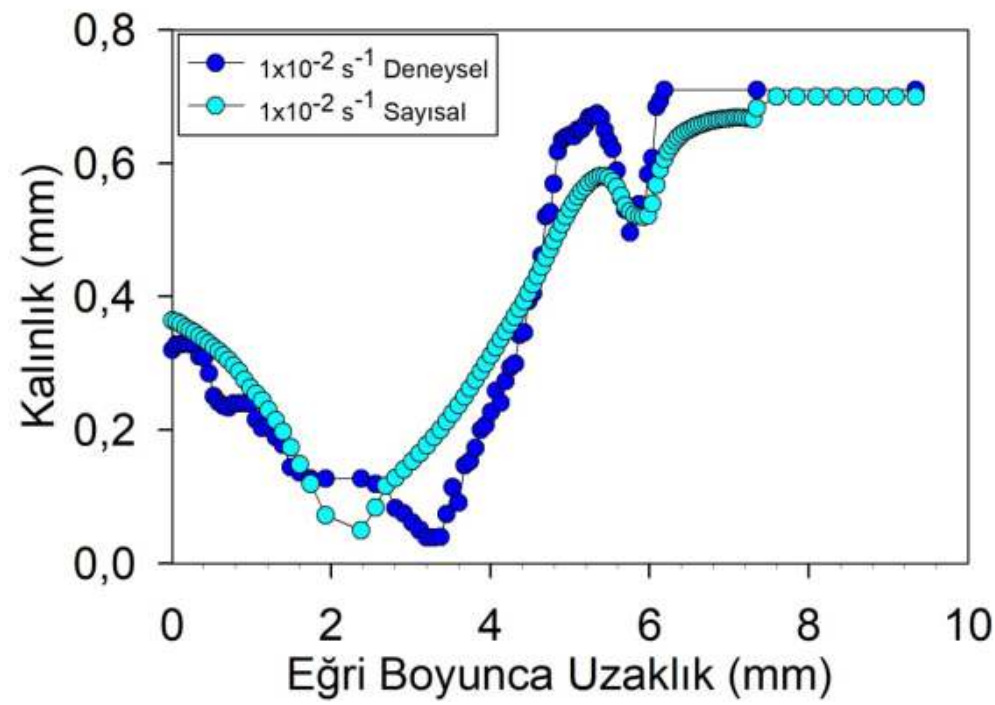

Şekil 4. $200 \mathrm{~nm}$ tane boyutundaki $\mathrm{Zn}-22 \mathrm{Al}$ alaşımının $1 \times 10^{-2} \mathrm{~s}^{-1}$ deformasyon hızında yapılan Erichsen testinde elde edilen parça kalınlığ değişimi 


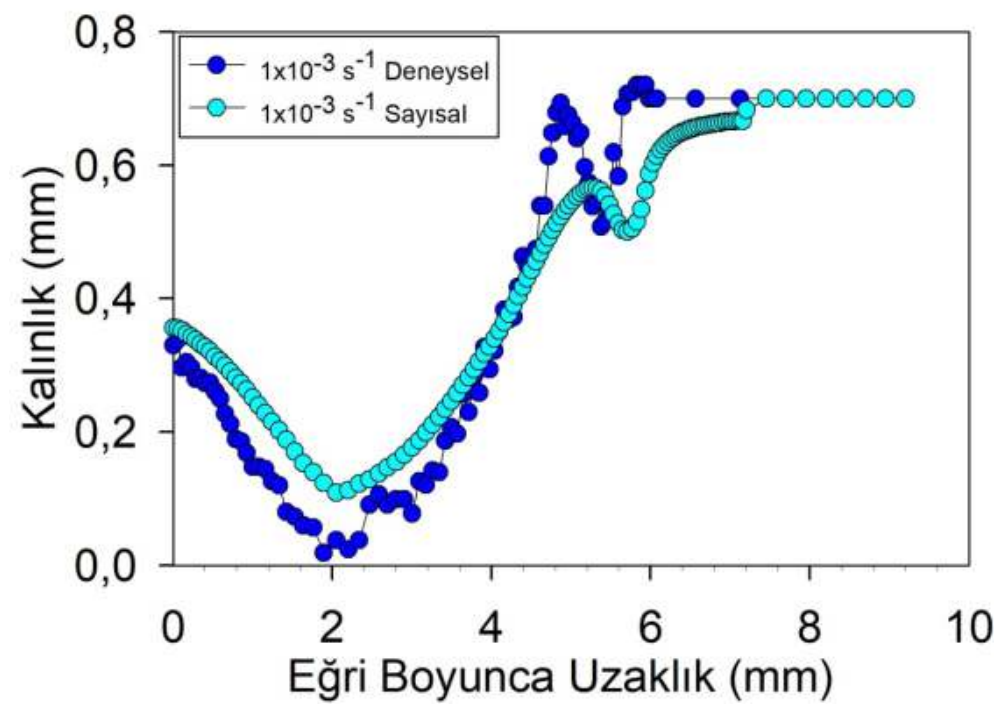

Şekil 5. Zn-22Al alaşımının $1 \times 10^{-3} \mathrm{~s}^{-1}$ deformasyon hızında yapılan Erichsen testinde elde edilen parça kalınlığ değişimi
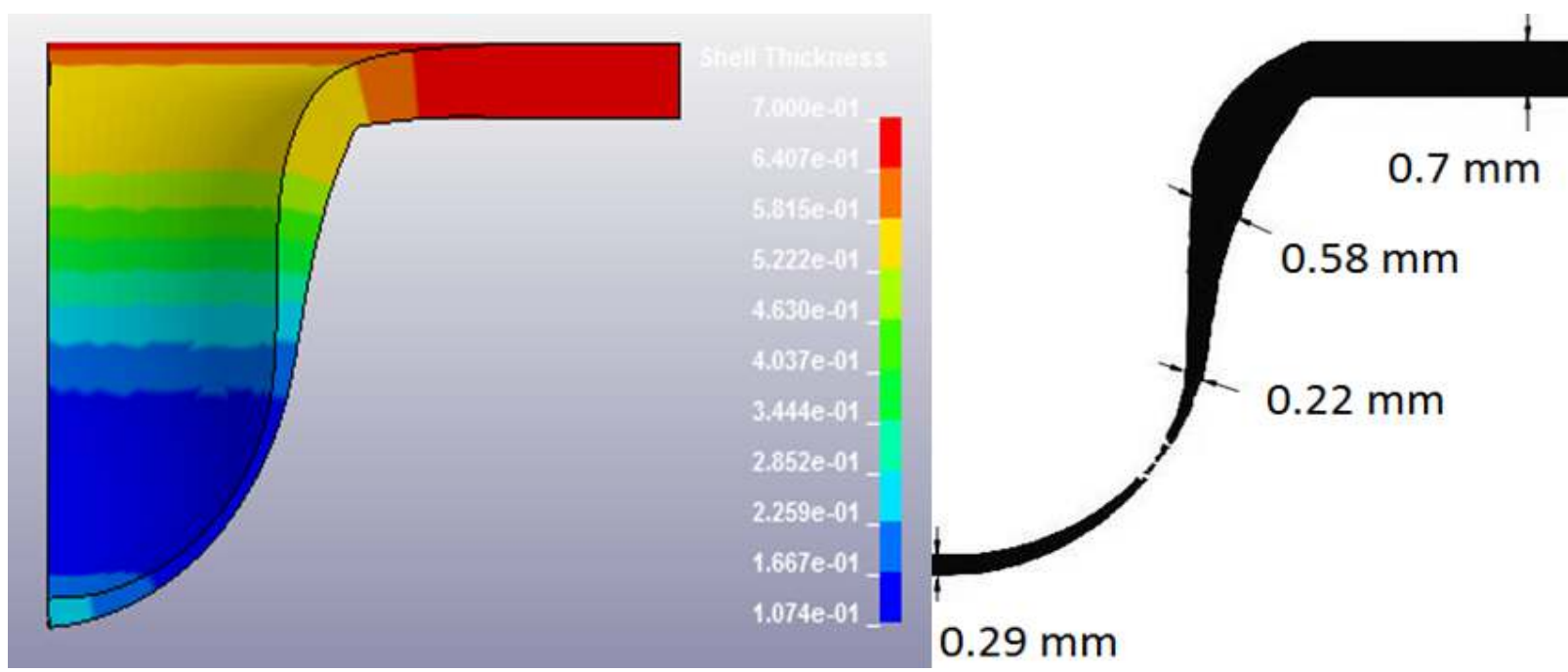

Şekil 5. Zn-22Al alaşımının $1 \times 10^{-1} \mathrm{~s}^{-1}$ deformasyon hızında yapılan Erichsen testinden elde edilen kesit resimlerinin karşılaştırılması

\section{Sonuçlar}

$\mathrm{Bu}$ çalışma kapsamında, süperplastik Zn-22Al alaşımının oda sıcaklığında şekillendirilebilirliği deneysel ve sayısal olarak incelenmiştir. Bu amaçla, ilk olarak döküm yoluyla elde edilen alaşım, eş kanallı açısal ekstrüzyon işlemine tâbi tutulmuş ve $200 \mathrm{~nm}$ tane boyutu elde edilmiştir. Daha sonra, numunelerin şekillendirilebilirliği farklı deformasyon hızlarında test edilmiştir. Öte yandan, Erichsen testlerinin sonlu eleman analizleri gerçekleştirilmiş ve numuneler üzerindeki kalınlık değişimleri deneysel sonuçlarla karşılaştırılmıştır. Deneysel ve sayısal sonuçlar 
karşılaştırıldığında Erichsen testine tabi tutulan numunelerdeki kalınlık dağılımının yüksek oranda uyum içinde olduğu görülmüştür. Öte yandan, oda sıcaklığında süperplastik davranış gösteren $\mathrm{Zn}-22 \mathrm{Al}$ alaşımının mikro imalat için uygun bir malzeme olabileceği sonucuna ulaşılmıştır.

\section{Referanslar}

[1] Langdon TG. Seventy-five years of superplasticity: Historic developments and new opportunities. J Mater Sci. 2009;44(22):5998-6010.

[2] Giuliano G. Superplastic Forming of Advanced Metallic Materials.; 2011.

[3] Kawasaki M, Langdon TG. Principles of superplasticity in ultrafine-grained materials. J Mater Sci. 2007;42(5):1782-1796.

[4] Tanaka T, Makii K, Ueda H, Kushibe A, Kohzu M, Higashi K. Study on practical application of a new seismic damper using a $\mathrm{Zn}-\mathrm{Al}$ alloy with a nanocrystalline microstructure. Int $\mathrm{J}$ Mech Sci. 2003;45(10):1599-1612.

[5] Valiev RZ, Langdon TG. Principles of equal-channel angular pressing as a processing tool for grain refinement. Prog Mater Sci. 2006;51(7):881-981.

[6] Xia SH, Wang J, Wang JT, Liu JQ. Improvement of room-temperature superplasticity in Zn22 wt.\%Al alloy. Mater Sci Eng A. 2008;493(1-2):111-115. doi:10.1016/j.msea.2007.07.100

[7] Uesugi T, Kawasaki M, Ninomiya M, Kamiya Y, Takigawa Y, Higashi K. Significance of Si Impurities on Exceptional Room-Temperature Superplasticity in a High-Purity Zn-22\%Al Alloy. Mater Sci Eng A. 2015; 645.

[8] Tanaka T, Makii K, Kushide A, Kohzu M, Higashi K. Capability of superplastic forming in the seismic device using Zn-22Al eutectoid alloy. Scr Mater. 2003;49(5):361-366.

[9] Hirata T, Tanaka T, Chung SW, Takigawa Y, Higashi K. Relationship between deformation behavior and microstructural evolution of friction stir processed Zn-22 wt.\% Al alloy. Scr Mater. 2007;56(6):477-480.

[10] Tanaka T, Watanabe H, Higashi K. Microstructure in Zn-Al Alloys after Equal-ChannelAngular Extrusion. Mater Trans. 2003;44(9):1891-1894.

[11] Demirtas M, Purcek G, Yanar H, Zhang ZJ, Zhang ZF. Improvement of high strain rate and room temperature superplasticity in $\mathrm{Zn}-22 \mathrm{Al}$ alloy by two-step equal-channel angular pressing. Mater Sci Eng A. 2015;620:233-240.

[12] Cetin ME, Demirtas M, Sofuoglu H, Cora ÖN, Purcek G. Effects of grain size on room temperature deformation behavior of $\mathrm{Zn}-22 \mathrm{Al}$ alloy under uniaxial and biaxial loading conditions. Mater Sci Eng A. 2016;672:78-87.

[13] Cetin ME. The Investigation of Micro Formability of Superplastic Zn-22Al Alloy on Room Temperature. PhD thesis (in Turkish), Karadeniz Technical University, Trabzon, Turkey 